\title{
PENGARUH DIKLAT KEPEMIMPINAN DAN PENGEMBANGAN KARIR TERHADAP KINERJA PEGAWAI DINAS KOPERASI UMKM PROVINSI SUMATERA BARAT
}

\author{
Nasfi $^{1 *}$, Rahmad $^{2}$, Sabri $^{3}$ \\ ${ }^{1}$ Lecturer Perbankan Syariah, STES Manna Wa Salwa, Padang Panjang, at Indonesia \\ email ; nasfi.anwar@gmail.com \\ 2,3 Lecture Prodi Manajemen, Sekolah Tinggi Ilmu Ekonomi Haji Agus Salim Bukittinggi \\ email ; rafa.dafa2013@gmail.com \\ email: sabrisimabur@gmail.com
}

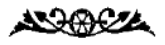

\begin{abstract}
This study aims to determine how the influence of leadership training and career development on the performance of employees of cooperatives, UMMs and trade in the Province of West Sumatra, the influence of leadership training on employee performance of cooperatives, UMMs and trade in West Sumatra Province influence the career development of staff and employees on employee performance the cooperative, umkm and trade service in W est Sumatra Province service and the influence of leadership training and career development on the performance of the cooperative, umkm and trade service employees of West Sumatra Province, the population in this study, a total of 25 people addressed to all members of the cooperative service employee, umkm and trade in West Sumatra Province, meaning that data retrieval is based on the census method ie the number of respondents is the same population as the sample. The analysis technique used is Multiple Linear Regression. The variables in this study use independent variables, namely leadership training (X1) and career development $(X 2)$ while performance $(Y)$ is the dependent variable. The results obtained by the equation $Y=0.417+0.630 X 1+0.987 X 2$, the significance value of the leadership training variable $(X 1)$ is 0.018 and career development $(X 2)$ is 0,000 which means that there is a significant and positive influence on leadership training (X1) on the performance (Y) of employees of the cooperative, umkm and trade services of West Sumatra Province there is a significant and positive influence on career development (X2) on the employees of the cooperative, umkm and trade service of West Sumatra Province.
\end{abstract}

Keywords: Diklat Kepemimpinan, Pengembangan Karir dan Kinerja

\section{PENDAHULUAN}

Peningkatan kualitas sumber daya manusia merupakan salah satu kunci keberhasilan pembangunan, hal ini dapat disadari mengingat manusia adalah merupakan subjek sekaligus objek dalam pembangunan nasional (Qurbani, 2019). Oleh karena itu pembangunan sumber daya manusia diarahkan agar mampu dan memiliki etos kerja yang produktif, kretif, inovatif, disiplin dan professional (Saputro
\& Prasetyo, 2015). Di samping itu juga memanfaatkan, mengembangkan dan menguasai ilmu dan teknologi yang inovatif dalam rangka memacu pelaksanaan pembangunan (Verawati, Widaryanti, \& Sugiharti, 2018).

Khususnya bagi aparatur Pemerintah Provinsi, peningkatan kompetensinya dewasa ini dirasakan sebagai kebutuhan yang mendesak, penting dan srategis (Hidayat, 2019). Hal ini didorong oleh 
kebutuhan persaingan di era global, implementasi, orentasi daerah dan sekaligus dalam upaya mewujudkan pemerintahan yang baik atau good governance (Kharisma, 2014). Undang-Undang Nomor 43 Tahun 1999 tentang Perubahan atas UndangUndang Nomor 8 Tahun 1974 tentang pokok-pokok kepegawaian menegaskan bahwa dalam rangka usaha mencapai tujuan nasional, diperlukan Pegawai Negeri Sipil (PNS) yang berkemampuan melaksanakan tugas secara professional (Kusuma, 2013). Untuk mewujudkan profesionalisme PNS ini muklak diperlukan peningkatan kompetensi, khususnya kompetensi kepemimpinan (Syukur, 2014).

Manajemen sumber daya manusia merupakan program, aktivitas untuk mendapatkan sumber daya manusia, mengembangkan, memelihara dan mendaya gunakaan, untuk mendukung organisasi mencapai tujuanya (Ardyawin, 2017). Sejalan dengan itu maka suatu organisasi perlu menciptakan, membina dan memperhatikan aspek-aspek yang bekaitan dengan sumberdaya manusia (Hasibuan, Mustapid, \& Wijaya, 2019).

Usaha memenuhi tuntutan kwalitas sumber daya manusia sebagai mana di sebutkan di atas sangat penting bagi suatu organisasi, terutama organisasi yang bergerak di bidang pelayanan, hal ini dikarenakan organisasi pelayanan berkaitan langsung dengan masyarakat atau orangorang yang menbutuhkan pelayanan tersebut (Rieuwpassa, Mantiri, \& Nayoan, 2019). Organisasi merupakan sistem sosial yang di rancang untuk mencapai tujuan tertentu, organisasi juga mempunyai sasaran ,yang hendak dicapainya, sasaran itu dapat diciptakan sebagai kondisi masa depan yang hendak dicapai oleh individu, kelompok atau organisasi (Adha, Qomariah, \& Hafidzi, 2019).

Pelayanan oleh lembaga-lembaga pemerintah kepada masyarakat disebut dengan istilah, seperti pelayanan masyarakat, pelayanan umum, atau pelayanan public (Hasan, 2019). Dalam Keputusan Menteri Pendayagunaan Aparatur Negara Nomor: 63/Kep/M.PAN/7/2003 yang dimaksud pelayanan publik adalah segala kegiatan pelayanan yang dilaksanakan oleh penyelengara pelayanan publik sebagai upaya pemenuhan kebutuhan penerima pelayanan maupun pelaksanaan ketentuan peraturan perundang - undangan (Menteri, 2003). Untuk mewujudkan profesionalisme PNS ini, muklak diperlukan peningkatan kompetensi kepemimpinan bagi para pejabat dan calon penjabat sruktural baik dilingkungan pemerintah pusat maupun daerah (Iswandi, Suhaimi, \& Gaussyah, 2017).

Organisasi harus menyadari bahwa untuk mencapai tujuan yang telah ditetapkan banyak faktor yang mempengaruhinya, salah satu faktor yang menentukan keberhasilan suatu organisasi adalah faktor sumber daya manusia yang berkualitas (Pituringsih, 2019). Sumber daya manusialah yang merancang dan mengaplikasikan semua rancangan yang menjadi target dari organisasi, mengingat pentingnya peran pengelola sumberdaya manusia dalam suatu organisasi agar dapat tetap survive dalam iklim persaingan bebas tanpa batas, maka peran manajemen sumberdaya manusia tidak lagi menjadi 
tangung jawab pegawai atau karyawan, akan terapai menjadi tanggung jawab organisasi (Shen \& Zhang, 2019).

Mengelola sumber daya manusia merupakan faktor penentu dalam mencapai tujuan organisasi, apabila faktor tenaga kerja dapat dikelola dengan baik dan tepat, maka penerapan sistem manajemen akan berhasil dalam penerapan, sistem manajemen akan mendorong tingkat perkembanagan organisasi dengan baik (Stewart \& Brown, 2019), secara internal pengelolaan karir sangat dipengaruhi oleh struktur organisasi, yang akan mengarahkan terbentuknya core managerial competencies, dan struktur organisasi akan memberi arah pada model pengelolaan karir (Bagdadli \& Gianecchini, 2019).

Dalam pengembangan karir Pegawai Negeri Sipil sebenarnya sudah jelas diatur dalam Peraturan Pemerintah Republik Indonesia Nomor 100 Tahun 2000 yang telah mengatur bahwa Pola Karir Pegawai Negeri sipil adalah Pola Pembinaan Pegawai Negeri Sipil yang menggambarkan jalur pengembangan karir dan menunjukan keterkaitan dan keserasian antara jabatan, pangkat, kompentensi, pendidikan dan pelatihan jabatan serta masa jabatan seseorang Pegawai Negeri Sipil sejak pengakatan pertama dalam jabatan tertentu sampai dengan pensiun (Yusniar, Suaib, \& Amir, 2019).

Kalau kita lihat dari pola pengembangan karir Pegawai Negeri Sipil tersebut diatas, pendidikan dan pelatihan jabatan didalam pengembangan karir mempuyai pengaruh terhadap pengembangan karir seseorang Pegawai Negeri Sipil (Marpaung, Nurlaela, \& Suruan, 2019). Tetapi fakta atau fenomena yang terjadi di Dinas Koperasi, UMKM dan Perdagangan Provinsi Sumatera Barat, pendidikan dan pelatihan terutama yang berhubungan dengan diklat kepemimpinan yang menunjang jabatan struktural seperti diklat kepemimpinan IV, III dan II tidak berpengaruh terhadap pengembangan karir seseorang karena dapat dilihat sekarang ini, banyak fenomena yang terjadi pejabat yang sudah menduduki jabatan tertentu belum mempuyai serifikat diklat kepemimpinan sesuai dengan jenjang jabatannya, dan sebaliknya banyak pejabat yang sudah mengikuti diklat kepemimpinan tetapi belum diberikan jabatan struktural sesuai dengan diklat kepemimpinanya. Melihat fenomena ini yang terjadi dilapangan atau di Dinas Koperasi, UMKM dan Perdagangan Provinsi Sumatera Barat penulis semakin tertarik untuk meneliti masalah ini apakah ada Pengaruh Diklat Kepemimpinan dan Pengembangan Karir terhadap Kinerja Pegawai Dinas Koperasi, UMKM dan Perdagangan Provinsi Sumatera Barat.

\section{KAJIAN TEORI}

\section{Diklat Kepemimpinan}

Menurut pasal 1 Peraturan Pemerintah Nomor 101 Tahun 2000 ditegaskan bahwa pendidikan dan pelatihan jabatan Pegawai Negeri Sipil yang selanjutnya disebut Pendidikan dan Pelatihan (DIKLAT) adalah penyelenggaraan proses belajar mengajar dalam rangka meningkatkan kemampuan pegawai negeri sipil dalam melaksanakan jabatannya (Yusniar et al., 2019). Salah satu tujuan pendidikan dan pelatihan adalah untuk meningkatkan 
pengetahuan, keahlian, ketrampilan dan sikap untuk dapat melaksanakan tugas jabatan secara profesional dengan dilandasi kepribadian dan etika pegawai negeri sipil sesuai dengan kebutuhan instansi (Tumurang \& Tuera, 2019).

Diklat kepemimpinan merupakan salah satu diklat yang dilasanakan oleh Badan Pelaksanaan Diklat yang bekerjasama dengan Badan Kepegawaian Daerah dan untuk peserta diklatpim adalah pegawai negeri sipil yang sudah memegang jabatan, ini dikarenakan setelah mengikuti diklatpim diharapkan pejabat dapat melaksankan tugasnya sebagai pemimpin yang profesional dalam menjalankan tugasnya dan mempuyai kesempatan yang lebih besar di dalam pengembangan karirnya (Rozi \& Anggraini, 2019).

Standar kompetensi Jabatan Strutural Pegawai Negeri Sipil telah ditetapkan melalui keputusan Kepala Badan Kepegawaian Negara No 43/KEP/2001, tanggal 20 juli 2001, adapun maksud ditetapkan standar kopetensi jabatan tersebut adalah sebagai dasar pengangkatan, pemindahan dan pemberhentian PNS dari dan dalam jabatan, selain itu dimaksud sebagai dasar penyusunan/pengembangan program pendidikan dan pelatihan bagi PNS (Rostanti, Yuniningsih, \& Djumiarti, 2016). Apabila dilihat dari maksud di atas, maka dapat dikatakan bahwa standar kompetensi jabatan sangat penting artinya terutama dalam mengangkat Pegawai Negeri Sipil untuk menduduki jabatan struktural haruslah yang betul-betul memiliki kopetensi yang telah ditetapkan dalam standar kopetensi jabatan (Lestari \& Nurislaminingsih, 2019).
Sementara itu tujuan ditetapkan stndar konpetensi jabatan adalah untuk efesiensi dan efektifitas pelaksanaan tugas dan tanggung jawab organisasi, selain itu bertujuan untuk menciptakan optimalisasi kinerja organisasi/unit organisasi (Sahambangung, Pioh, \& Waworundeng, 2019), apabila dilihat dari tujuannya, maka standar kopetensi jabatan dapat digunakan untuk efisiensi dan efektifitas pelaksanaan tugas dan tanggung jawab organisasi sehingga organisasi akan mampu bekerja lebih efisien dan akan menciptakan optimalisasi kinerja organisasi (Habe, 2019).

Pendidikan dan pelatihan sering di sebut dengan diklat merupakan salah satu upaya yang dapat dilakukan oleh organisasi dalam rangka meningkatkan pendidikan, keterampilan, kopentensi serta kinerja karyawan/pegawainya.oleh karena itu pendidikan dan pelatihan (diklat) bagi suatu organisasi haruslah dipandang sebagai suatu investasi jangka panjang dibidang sumber daya manusia (Suparwo, Suhendi, \& Shobary, 2019).

Pengertian diklat oleh Walker (1992: 112) didefinisikan untuk menunjukkan pentingnya peran diklat bagi suatu organisasi, yakni bahwa selain sebagai sarana untuk meningkatkan kemampuan dan keterampilan pegawai dalam kinerja dan melaksanakan tugasnya, diklat juga merupakan sarana yang penting bagi pihak manajemen dalam dalam menerapkan strategi organisasi (Ju \& Li, 2019). Melalui pemberian diklat pengetahuan dan keterampilan semakin bertambah sehingga meningkatkan kinerjanya, jadi ada hubungan langsung antara pemberian diklat 
dengan peningkatan kinerja pegawai (Carrion, Miltenberger, \& Quinn, 2019).

Pengertian pendidikan dan pelatihan mengandung arti yang berbeda seperti yang di bahwa, pendidikan bersifat filosofis dan teoritis, sedangkan pelatihan bersifat spesifik dan praktis, meskipun demikian pendidikan dan pelatihan mempunyai persamaan yaitu melakukan pembelajaran, dimana dalam proses tersebut terdapat kegiatan kognitif, afektif, dan psikomotor (D'Isanto, D'Elia, Raiola, \& Altavilla, 2019).

Pelatihan pengembangan SDM proses memperbaiki kinerja pegawai/karyawan dalam melaksanakan tugasnya dalam suatu organisasi yang dilakukan dengan memberikan atau meningkatkan kinerja seseorang, memberikan pengertian pelatihan dan pengembangan, dengan mendifinisikan pelatihan (Training) sebagai suatu proses pendidikan jangka pendek dengan menggunakan prosedur yang sistematis dan terorganisir di mana pegawai non manajerial mempelajari pengetahuan dan ketrampilan teknis sebagai tujuan yang terbatas (Morgeson, Brannick, \& Levine, 2019). Sedangkan pengembangan (Development) merupakan suatu proses pendidikan jangka panjang yang menggunakan prosedur sistematis dan terorganisir di mana pegawai manajerial mempelajari pengetahuan konseptual dan teoritis guna mencapai tujuan umum (Cho, Bong, \& Kim, 2019).

Dengan demikian berdasarkan teori da istilah diatas dapat disimpulak bahwa, pendidikan merupakan pengembangan kemampuan sumber daya manusia untuk jangka panjang yang telah teroganisis atau terjadwal dengan baik, sedangkan pelatihanan adalah merupakan proses pendidikan yang berjangka pendek dan berualang-ulang untuk meningkatkan kemampuan, pengetahuan dan displin kerja sumber daya manusian untuk mencapai kinerja dalam organisasi sesuai dengan jabatan dan fungsinya.

\section{Pengembangan Karir}

Pengertian tentang karir yakni suatu rangkaian (urutan) posisi atau jabatan yang ditempati sesorang selama kehidupan tertentu, suatu perubahan nilai-nilai, sikap dan motivasi yang terjadi pada seseorang karena dengan penambahan/peningkatan usianya akan menjadi semakin matang, dan sesuatu usaha yang dilakukan secara formal dan berkelanjutan dengan difokuskan pada penambahan dan peningkatan kemampuan seorang pekerja (Quigley \& Tymon Jr, 2006). Berdasarkan ungkapan tersebut dapat disimpulkan bahwa kecakapan atau prestasi kerja, pengalaman, pelatihan dan pengembangan diri seseorang dalam berkerja sangat berperan penting dalam pengembangan jenjang jabatan atau karier seseorang. Begitu juga pendapat dari (Okereke, 2011) bahwa ada hubungan langsung antara prestasi kerja atau kinerja, pengalaman atau masa kerja, pelatiahan dan pengembangan dengan pengembangan karir (Okereke \& Nnenna, 2011).

Undang-Undang Republlik Indonasia Nomor 43 Tahun 1999 disebutkan bahwa bagian dari pembinaan pegawai negeri, perlu dilakukan dengan sebaik-baiknya dengan berdasarkan pada perpaduan sistem prestasi kerja, hal ini dimaksudkan untuk peluang bagi PNS yang berprestasi tinggi untuk meningkatkan kemampuannya secara 
propesional dan berkkopetensi secara sehat (Kusuma, 2013). Dari penjelasan-penjelasan diatas bahwa PNS diangkat pada jabatan dan posisi terntentu harus memiliki prestasi, kompetensi serta pendidikan dan pelatihan yang dimiliki oleh pegawai yang bersangkutan. Karir berarti semua pekerjaan yang dipegang dan menjadi tanggung jawab seseorang selama ia bekerja (Wang, Zhao, Liu, An, \& Pan, 2019).

\section{Kinerja}

Definisi kinerja adalah gambaran umum pencapaian program atau kebijakan dalam mewujudkan tujuan, sasaran, misi dan visi suatu organisasi yang dilakukan oleh staff dan karyawan dalam menjacapai tujuan organisasi (Nasfi, Iska, Nofrivul, \& Antoni, 2019). Kinerja merupakan hasil kerja yang dicapai oleh seseorang pegawai dalam melaksanakan tugas dan tanggung jawab sesuai dengan job description dan waktu yang ditentukan (Sánchez-Marín, Meroño-Cerdán, \& Carrasco-Hernández, 2019). Kinerja merupakan hasil kerja seorang pekerja, sebuah proses manajemen atau suatu organisasi secara keseluruhan, dimana hasil kerja tersebut harus dapat dibuktikan secara konkret dan dapat diukur (Arif, 2019). Diman kinerja organisasi, kinerja proses, dan kinerja pekerja satu sama lain tidak dapat dipisahkan, di mana kinerja organisasi tergantung dari proses manajemen, administrias dan proses produksi, dan kinerja pekerja tergantung baik tidaknya kinerja organisasi dan kinerja proses (Aydiner, Tatoglu, Bayraktar, \& Zaim, 2019).

Faktor-faktor yang mempengaruhi kinerja pegawai di pengaruhi oleh berbagai hal, yaitu: spesifikasi jabatan, sarana dan mekanisme kinerja, impak kinerja, mekanisme umpan balik, dan faktor internal pegawai. Jadi setiap kenerja harus bersifat nyata dan dapat diukur serta membutuhkan sarana dan mekanisme alur yang jelas, membutuhkan suatu sisitem umpan balik (feedback) sebagai alat kontrol kualitas,agar dengan umpan balik itu kinerja dapat dipertahankan pada posisi kualitas yang optimal (Huselid, 1995).

Kinerja juga tidak bisa terlepas dari faktor atau kondisi internal pegawai atau pekerja yang menghasilkan kinerja tersebut, faktor internal ini meliputi kamampuan intelektual (kognitif), kemampuan psikomotorik (gerak) dan sikap (afektif) (Londok, 2019). Faktor internal ini merupakan faktor yang dapat menghasilkan kinerja dan dapat ditingkatkan melalui proses pembelajaran (Faisal \& Lestari, 2019), menjelaskan bahwa kekurangan dalam setiap atau ketiga faktor tersebut dapat mengakibatkan kinerja yang tidak cukup.dari hal tersebut dapat di simpulkan kinerja dapat ditingkatkan melalui prosees pendidikan dan pelatihan (Ambarwati \& Baehaqi, 2019), faktor ekternal yang mempengaruhi kinerja karyawan dalam mencapai prestasi kerja dan kinerja berupa lingkungan kerja menjadi tanggungjawab individu yang bersangkutan saat ini, sedangkan pengembangan proses peningkatan kemampuan individu untuk masa yang akan dating (Arisanti, Santoso, \& Wahyuni, 2019).

Untuk meningkatkan kinerja karyawan perlu dilakukan penilaian pekerjaan secara wajar berupa prestasi kerja (kuantitas dan kualitas), pengetahuan 
pekerjaan, inisiatif dalam bekerja, kecakapan mental, sikap dalam bekerja maupun disiplin selama jam kerja berlangsung (Munir, 2019).

\section{Kerangka Konseptual}

Seperti yang diungkapkan diatas sebelumnya pendidikan pelatihan merupakan sarana untuk meningkatkan pengetahuan, kemampuan dan keterampilan pegawai dalam meningkatkan kinerja. Bahwa keberhasilan usaha, keselamatan kerja dan produtifitas kerja dapat dipelihara dan ditingkatkan dengan pelatihan karyawan, artinya pelatihan dimadsudkan untuk menciptakan keterampilan dan keahlian karyawan. Berdasarkan kerangka toeritis dan peryataan tersebut diatas menunjukan bahwa ada hubungan lansung antara pemberian diklat dengan peningkatan kinerja pegawai (Utami, 2019). Penelitian tentang Pengaruh Diklat Kepemimpinan Dan Karakteristik Pejabat Terhadap Kinerja Dan Pengembangan Karir Pejabat Struktural Di Badan Pengkajian Dan Penerapan Teknologi (BPPT), hasil dari penelitianya Diklat Kepemimpinan memberikan pengaruh secara signifikan terhadap pengembangan karir pejabat struktural di BPPT (Trihadi, 2003)

Tujuan pendidikan, pelatihan dan pengembangan karyawan adalah untuk memperbaiki efektifitas kerja karyawan dalam mencapai hasil-hasil kerja yang telah ditetapakan, peningkatan efetifitas kerja dapat dilakukan dengan latihan (training) dan atau pengembanagan (develoment) (Abdullah, 2014). Penelitian yang dilakukan oleh Dini dan Sari (2013) disimpulkan bahwa pelatihan yang diikuti karyawan dengan baik sehingga karyawan dapat belajar langsung kelapangan dan tidak selamanya kinerja karyawan kurang baik, Penelitian yang dilakukan Lubis (2009), dengan hasil bahwa pendidikan dan pelatihan penagawai negeri sipili di lingkungan pemda sumatera barat dengan hasil meningkatkan kinerja pegawai negeri sipil (Lubis, 2009).

Berdasarkan kajian teori diatas, maka kerangka pemikiran sebagai berikut:

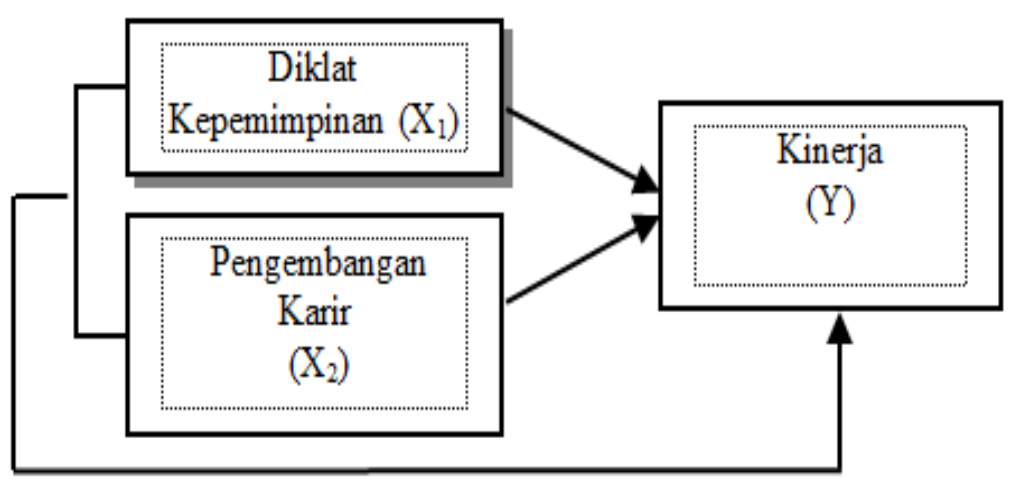

\section{Gambar 1: Kerangka Pemikiran}

Hipotesis Penelitian adalah diklat koperasi, umkm dan perdagangan Provinsi kepemimpinan berpengaruh positif dan Sumatera Barat dan pengembangan karir signifikan terhadap kinerja pegawai dinas berpengaruh positif dan signifikan terhadap 
kinerja pegawa dinas koperasi, umkm dan perdagangan Provinsi Sumatera Barat.

\section{METODE PENELITIAN}

Lokasi penelitian ini adalah dinas koperasi, umkm dan perdagangan Provinsi Sumatera Barat. Pemilihan tempat penelitian didasarkan atas karekteristik kelayakan objek yang sangat memungkinkan untuk mendapatkan informasi, yang akan menunjang tercapainya tujuan penelitian. Populasi dalam penelitian ini, terdiri dari semua elemen yang terkait yakni seluruh dinas koperasi, umkm dan perdagangan Provinsi Sumatera Barat.

Adapun populasi pada penelitian ini, sejumlah 25 orang yang ditujukan pada seluruh dinas koperasi, umkm dan perdagangan Provinsi Sumatera Barat, artinya pengambilan data berdasarkan metode sensus yaitu jumlah responden populasi sama dengan sampel. Hasil uji validitas pada variabel penelitian adalah variabel diklat kepemimpinan (X1) diukur dengan menggunakan 8 pernyataan, yang mana semua butir pernyataan yang digunakan adalah valid karena semua butir pernyatan memiliki nilai $r$ hitung lebih besar dari $r$ tabel $(0,367)$, variabel pengembangan karir (X2) diukur dengan menggunakan 8 pernyataan, yang mana semua butir pernyataan yang digunakan adalah valid karena semua butir pernyatan memiliki nilai r hitung lebih besar dari $r$ tabel $(0,367)$ dan variabel kinerja (Y) diukur dengan menggunakan 8 pernyataan, yang mana semua butir pernyataan yang digunakan adalah valid karena semua butir pernyatan memiliki nilai $\mathrm{r}$ hitung lebih besar dari $\mathrm{r}$ tabel $(0,367)$.

Hasil reliabilitas pada penelitian ini adalah nilai croanbach's alpha untuk dimensi Kinerja (Y) adalah 0,788 sedangkan nilai croanbach's alpha untuk variabel diklat kepemimpinann (X1) adalah 0,776 dan pengembangan karir (X2) adalah 0,785. Secara menyeluruh bahwa semua variabel dalam penelitian ini memiliki nilai croanbach's alpha di atas 0,60. Dengan demikian semua variabel penelitian ini adalah reliable atau andal.

\section{HASIL PENELITIAN DAN PEMBAHASAN}

\section{Deskripsi Variabel Penelitian}

Kinerja (Y) merupakan variabel terikat, yang diukur dengan menggunakan 8 butir pernyataan. Dari 8 pernyataan kinerja dinas koperasi, umkm dan perdagangan Provinsi Sumatera Barat menunjukan nilai presentase pada kategori baik.Hal ini dapat dilihat dari skor tingkat capaian responden (TCR) sebesar 87,10.

Diklat Kepemimpinan (X1) merupakan variabel Bebas, yang diukur dengan menggunakan 8 butir pernyataan. Dari 8 pernyataan diklat kepemimpinan dinas koperasi, umkm dan perdagangan Provinsi Sumatera Barat menunjukan nilai presentase pada kategori baik.Hal ini dapat dilihat dari skor Tingkat capaian responden (TCR) sebesar 86,30.

Pengembangan Karir (X2) merupakan variabel bebas, yang diukur dengan menggunakan 8 butir pertanyaan. Dari 8 pernyataan pengembangan karir pegawai dinas koperasi, umkm dan perdagangan 
Provinsi Sumatera Barat menunjukan nilai presentase pada kategori baik.Hal ini dapat dilihat dari skor Tingkat capaian responden (TCR) sebesar 87,70.

\section{Hasil Uji Statistik}

Uji Asumsi Klasik

Uji Normalitas, Hasil perhitungan uji normalitas adalah:

\section{Rangkuman Uji Normalitas Variabel Penelitian}

\begin{tabular}{|l|r|r|r|}
\hline & \multicolumn{1}{|c|}{$\begin{array}{c}\text { Diklat } \\
\text { Kepemimpinen } \\
\text { (X1) }\end{array}$} & $\begin{array}{c}\text { Pengemba } \\
\text { nga } \\
\text { Karir(X2) }\end{array}$ & \multicolumn{1}{|c|}{$\begin{array}{c}\text { Kinerja } \\
(\mathrm{Y})\end{array}$} \\
\hline $\mathrm{N}$ & 25 & 25 & 25 \\
$\begin{array}{l}\text { Kolmogorov- } \\
\text { Smirnov Z }\end{array}$ &, 955 &, 654 &, 726 \\
$\begin{array}{l}\text { Asymp. Sig. (2- } \\
\text { tailed) }\end{array}$ & $\mathbf{, 3 2 1}$ & $\mathbf{, 7 8 6}$ & $\mathbf{, 6 6 8}$ \\
\hline
\end{tabular}

Sumber: Olahan Data Primer 2017

Hasil uji normalitas diketahuinilai nilai Asym.Sig (2-tailed) untuk variabel diklat kepemimpinan (X1) sebesar 0,321 dan pengembangan karir (X2) sebesar 0,786, sedangkan kinerja (Y) sebesar 0,668. Jadi, dapat disimpulkan bahwa nilai Asym.Sig (2tailed) dari semua variabel penelitian nilainya lebih besar dari tingkat signifikan yang digunakan pada penelitian ini $(\alpha$ $=0,05)$. Dapat disimpulkan bahwa semua variabel penelitian berdistribusi normal, berarti analisis regresi dapat dilaksanakan karena data telah berdistribusi normal.

Uji Heteroskedastisitas, Untuk mendeteksi ada atau tidaknya heteroskedastisitas dapat dilakukan dengan melihat Grafik Plott (Scatter plot). Gambar : Grafik Plott ( Scatter Plot)

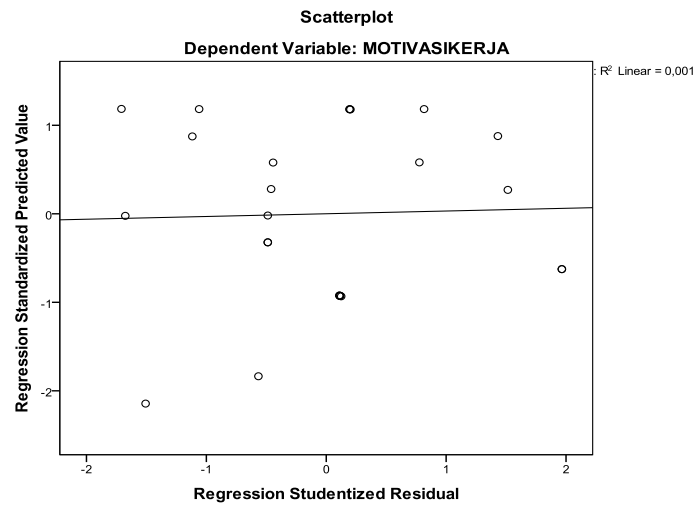

Pada gambar Grafik Plott (Scatter plot) pada penelitian ini tidak terdapat pola yang jelas, yang mana titik menyebar di atas dan dibawah angka 0 (nol) pada sumbu $\mathrm{Y}$, maka dapat disimpulkan bahwa tidak terdapat heteroskedastisitas.

UjiMultikolinearitas, Hasil uji multikolineritas dapat dilihat pada tabel berikut ini :

\section{Hasil U ji Multikolinearitas} Coefficients(a)

\begin{tabular}{|c|c|c|c|}
\hline \multirow[t]{2}{*}{ Model } & & \multicolumn{2}{|c|}{$\begin{array}{l}\text { Collinearity } \\
\text { Statistics }\end{array}$} \\
\hline & & $\begin{array}{l}\text { Toleranc } \\
\mathrm{e}\end{array}$ & VIF \\
\hline 1 & (Constant) & & \\
\hline & Diklat & ,392 & 2.549 \\
\hline
\end{tabular}




\begin{tabular}{|l|l|r|r|}
\hline & $\begin{array}{l}\text { Kepemimpin } \\
\text { an }\end{array}$ & & \\
\hline $\begin{array}{l}\text { Pengembang } \\
\text { an Karir }\end{array}$ &, 392 & 2,549 \\
\hline
\end{tabular}

Sumber: Olahan Data Primer 2017

Berdasarkan hasil olahan data diketahui bahwa nilai tolerance dari Collinearity Statistics mendekati 1 (satu) dan nilai VIF (Variance Inflation Factor) untuk semua variabel bebas dibawah 10 (sepuluh). Hal ini menunjukkan bahwa tidak terdapat kasus multikolinearitas antara sesama variabel bebas. Oleh karena itu dapat disimpulkan bahwa data hasil penelitian ini dapat dilakukan pengolahan data dengan regresi linear berganda karena tidak terdapat kasus multikolinearitas antara sesama variabel bebas.

\section{Hasil Analisis Penelitian}

Untuk membuktikan hipotesis yang diajukan, digunakan pendekatan OLS (Ordinal Least Square) atau metode kuadrat terkecil yang dibentuk oleh dua variabel bebas, yaitu variabel diklat kepemimpinan (X1)dan Pengembangan karir(X2) dan satu variabel terikat yaitu kinerja (Y), untuk menguji hipotesis pada penelitian ini digunakan teknik analisis regresi linear berganda. Hasil analis regresi linear berganda dari variabel penelitian yaitu diklat kepemimpinan (X1)dan pengembangan karir (X2), sebagai variabel independen dan satu variabel terikat yaitu kinerja $(\mathrm{Y})$ sebagai variabel dependent diperoleh persamaan sebagaimana ditampilkan pada Tabel berikut ini:

\section{Hasil Analisis Penelitian}

\begin{tabular}{|l|l|r|r|r|}
\hline No & Variabel & $\begin{array}{c}\text { Koefisien } \\
\text { Regresi }\end{array}$ & $\mathrm{t}$ & Sig. \\
\hline & (Constant) &, 417 & 5,484 &, 002 \\
\hline
\end{tabular}

\begin{tabular}{|l|l|r|r|r|}
\hline 1 & $\begin{array}{l}\text { Diklat } \\
\text { Kepemimpinan }\end{array}$ &, 630 & 4,036 &, 018 \\
\hline 2 & $\begin{array}{l}\text { Pengembangan } \\
\text { Karir }\end{array}$ &, 987 & 5,962 &, 000 \\
\hline
\end{tabular}

Sumber: Olahan Data Primer 2017

Dari hasil pengolahan data untuk analisis regresi linear berganda sebagaimana yang terlihat pada Tabel terlihat nilai koefisien regresi dari masing-masing variabel penelitian yang dapat disubstitusikan ke dalam persamaan regresi berganda sebagai berikut:

$$
\begin{aligned}
& Y=a+b_{1} X_{1}+b_{2} X_{2}+e \\
& Y=0,417+0,630 X_{1}+0,987 X_{2}
\end{aligned}
$$

Nilai koefisien yang disubsitusikan ke dalam persamaan di atas dapat diartikan sebagai berikut:

1) Nilai konstanta sebesar 0,417 , hal ini menunjukkan bahwa Jika tidak ada diklat kepemimpinan (X1) dan pengembangan karir (X2), maka nilai kinerja (Y) sebesar 0,417 .

2) Koefisien regresi dari diklat kepemimpinan (X1) sebesar 0,630 yang bertanda positif menunjukkan bahwa dengan semakin tingginya diklat kepemimpinan (X1) akan meningkatkan kinerja (Y) sebesar 0,630 dalam setiap satuan dengan asumsi variabel lain tidak mengalami perubahan (catteries paribus).

3) Koefisien regresi dari pengembangan arir (X2) sebesar 0,987 yang bertanda positif, menunjukkan bahwa dengan semakin tingginya pengembangan karir (X2) akan meningkatkan kinerja $(\mathrm{Y})$ sebesar 0,987 dalam setiap satuan dengan asumsi variabel lain tidak mengalami perubahan (catteries paribus).

Uji Partial (Uji t)bertujuan melihat pengaruh signifikan dari variabel indipendent terhadap variabel dependent 
dan melihat variabel yang memiliki pengaruh yang dominan terhadap variabel dependent, maka dari hasil penelitian dapat diketahui:

1) Hipotesis Pertama (H1): diklat kepemimpinan (X1) berpengaruh signifikan terhadap kinerja ( $\mathrm{Y}$ ) pegawai dinas koperasi, umkm dan perdagangan Provinsi Sumatera Barat.

Nilai signifikansi dari variabel diklat kepemimpinan (X1)adalah sebesar 0,018. Jika nilai signifikansi dibandingkan dengan tingkat signifikan yang digunakan dalam penelitian ini $(\alpha=0,05)$ maka terbukti bahwa nilai signifikansi lebih kecil dari tingkat signifikan yang digunakan $(0,018<0,05)$. Hal ini berarti terdapat pengaruh yang signifikan dan positif diklat kepemimpinan (X1) terhadap kinerja $(\mathrm{Y})$ pegawai dinas koperasi, umkm dan perdagangan Provinsi Sumatera Barat.

2) Hipotesis Dua (H2): pengembangan karir (X2) berpengaruh signifikan terhadap kinerja (Y) pegawai dinas koperasi, umkm dan perdagangan Provinsi Sumatera Barat.

Nilai signifikansi dari variabel pengembangan karir (X2) adalah sebesar 0,000. Jika nilai signifikansi dibandingkan dengan tingkat signifikan yang digunakan dalam penelitian ini $(\alpha=0,05)$ maka terbukti bahwa nilai signifikansi lebih kecil dari tingkat signifikan yang digunakan $(0,000<0,05)$. Hal ini berarti terdapat pengaruh yang signifikan dan positif pengembangan karir (X2) terhadap kinerja $(\mathrm{Y})$ pegawai dinas koperasi, umkm dan perdagangan Provinsi Sumatera Barat.

Uji F (Uji Regresi secara keseluruhan), untuk menguji signifikansi pengaruh variabel-variabel independen (X1i-X3i) secara keseluruhan terhadap variabel dependen (YYi). Sebagaimana yang ditampilkan dalam tabelberikut ini :

Hasil Uji F : ANOVA(b)

\begin{tabular}{|c|c|c|c|c|c|c|}
\hline $\begin{array}{l}\text { Mo } \\
\text { del }\end{array}$ & & $\begin{array}{l}\text { Sum } \\
\text { of } \\
\text { Squa } \\
\text { res }\end{array}$ & $\mathrm{df}$ & $\begin{array}{l}\text { Mea } \\
\mathrm{n} \\
\text { Squa } \\
\text { re }\end{array}$ & $\mathrm{F}$ & Sig. \\
\hline 1 & $\begin{array}{l}\text { Regressi } \\
\text { on } \\
\text { Residua } \\
1 \\
\text { Total }\end{array}$ & $\begin{array}{r}254, \\
881 \\
62,4 \\
79 \\
317, \\
360\end{array}$ & $\begin{array}{l}2 \\
2 \\
2 \\
4\end{array}$ & $\begin{array}{r}127 \\
441 \\
2,84 \\
0\end{array}$ & $\begin{array}{r}44,8 \\
74\end{array}$ & $\begin{array}{r}, 000( \\
\text { a) }\end{array}$ \\
\hline
\end{tabular}

a Predictors: (Constant), Lingkungan Kerja X2, Kualitas SDM X1

b Dependent Variable: Motivasi Kerja Y

Dari tabel diketahui nilai $\mathrm{F}$ adalah 44,874 dengan $\propto$ 0,000, maka dapat diartikan bahwa diklat kepemimpinan X1)dan pengembangan karir (X2) memiliki pengaruh yang nyata (signifikan) dengan variabel kinerja (Y) pegawai dinas koperasi, umkm dan perdagangan Provinsi Sumatera Barat.

Koefisien determinasi R2, pada penelitian ini dapat dilihat pada tabel berikut ini:

HasilKoefisien determinasi R2 Model Summary

\begin{tabular}{|l|c|c|c|c|}
\hline Model & $\mathrm{R}$ & $\begin{array}{c}\mathrm{R} \\
\text { Square }\end{array}$ & $\begin{array}{c}\text { Adjusted } \\
\mathrm{R} \text { Square }\end{array}$ & $\begin{array}{c}\text { Std. Error of } \\
\text { the Estimate }\end{array}$ \\
\hline 1 &, $896^{\mathrm{a}}$ &, 803 &, 785 & 1,68522 \\
\hline
\end{tabular}

a Predictors: (Constant), diklat

kepemimpinan X1,Pengembangan karir X2

Berdasarkan tabel diatas dapat dilihat bahwa nilai $\mathrm{R}$ Square sebesar 0,803, maka dapat disimpulkan bahwa nilai $\mathrm{R}$ Square 
mendekati angka 1 (satu), maka pengaruh antara variable diklat kepemimpinan (X1) dan pengembangan karir (X2) dengan variabel kinerja $(\mathrm{Y})$ semakin kuat.

\section{PEMBAHASAN}

\section{Pengaruh diklat kepemimpinan terhadap kinerja pegawai dinas koperasi, umkm dan perdagangan Provinsi Sumatera Barat.}

Berdasarkan hasil pengujian hipotesa diketahui bahwa diklat kepemimpinan berpengaruh signifikan dan positif terhadap kinerja pegawai dinas koperasi, umkm dan perdagangan Provinsi Sumatera Barat.

Dari analisis regresi rinier berganda diperoleh bahwa nilai koefisien regresi variabel diklat kepemimpinan (X1) sebesar 0,630 dengan nilai signifikansi sebesar 0,018. Jika nilai signifikansi dibandingkan dengan tingkat signifikan yang digunakan dalam penelitian ini $(\alpha=0,05)$ maka terbukti bahwa nilai signifikansi lebih kecil dari tingkat signifikan yang digunakan $(0,018<0,05)$. Dari koefisien regresi diketahui pengaruh diklat kepemimpinan terhadap kinerja sebebesar 0,630 bertanda positif, yang menunjukkan bahwa dengan peningkatan dari diklat kepemimpinan (X1) akan meningkatkan kinerja (Y) sebesar 0,630 .

Variabel diklat kepemimpinan dalam kondisi baik. Hal ini dapat dilihat dari score tingkat capaian responden (TCR) sebesar 86,30. Penelitian ini sesuai dengan pendapat dari oleh Walker (1992: 112) diklat didefinisikan untuk menunjukkan pentingnya peran diklat bagi suatu organisasi, yakni bahwa selain sebagai sarana untuk meningkatkan kemampuan dan keterampilan pegawai dalam kinerja dan melaksanakan tugasnya, diklat juga merupakan sarana yang penting bagi pihak manajemen dalam dalam menerapkan strategi organisasi. Melalui pemberian diklat pengetahuan dan keterampilan semakin bertambah sehingga meningkatkan kinerjanya, jadi ada hubungan langsung antara pemberian diklat dengan peningkatan kinerja pegawai.

\section{Pengaruh pengembangan karir terhadap kinerja pegawai dinas koperasi, umkm dan perdagangan} Provinsi Sumatera Barat.

Berdasarkan hasil pengujian hipotesa diketahui bahwa pengembangan karir berpengaruh signifikan dan positif terhadap kinerja pegawai dinas koperasi, umkm dan perdagangan Provinsi Sumatera Barat. Temuan penelitian ini membuktikan semakin baik pengembangan karir tentunya akan meningkatkan kinerja pegawai dinas koperasi, umkm dan perdagangan Provinsi Sumatera Barat.

Dari analisis regresi linier berganda diperoleh bahwa nilai koefisien regresi variabel pengembangan karir (X2) sebesar 0,978 dengan nilai signifikansi sebesar 0,000. Jika nilai signifikansi dibandingkan dengan tingkat signifikan yang digunakan dalam penelitian ini $(\alpha=0,05)$ maka terbukti bahwa nilai signifikansi lebih kecil dari tingkat signifikan yang digunakan $(0,000<0,05)$. Dari koefisien regresi diketahui bahwa pengaruh pengembangan karir terhadap kinerja sebesar 0,978 bertanda positif, yang menunjukkan bahwa dengan peningkatan dari pengembangan karir (X2) akan meningkatkan kinerja (Y) sebesar 0,978. Variabel Pengembangan karir berkategori baik, hal ini dapat dilihat dari 
skor Tingkat capaian responden (TCR) yaitu sebesar 87,70.

Penelitian ini sesuai dengan pendapat dari Nawawi (2000:289) mengemukakan beberapa pengertian tentang karir yakni suatu rangkaian (urutan) posisi atau jabatan yang ditempati sesorang selama kehidupan tertentu, suatu perubahan nilai-nilai, sikap dan motivasi yang terjadi pada seseorang karena dengan penambahan/peningkatan usianya akan menjadi semakin matang, dan sesuatu usaha yang dilakukan secara formal dan berkelanjutan dengan difokuskan pada penambahan dan peningkatan kemampuan seorang pekerja.

PP No. 100 Tahun 2000 Bab II Pasal 7 menegaskan kewajiban PNS yang diangkat dalam jabatan struktural untuk mengikuti Diklatpim sesuai dengan tingkat jabatan struktural, selanjutnya ketentuan lain-lain keputusan Kepala Badan Kepegawaian Negara Nomor 12 Tahun 2001, menegaskan sanksi atau konsekuensi bagi pejabat yang tidak mengikuti Diklatpim sampai batas waktu yang telah ditentukan. Ketentuan tersebut menuntut seluruh pejabat struktural untuk dapat mengikuti Diklatpim sehingga dengan telah mengikuti Dilatpim, seseorang pegawai negeri sipil yang mempuyai kesempatan yang lebih besar di dalam pengembangan karirnya.

Arilia (2008) melakukan penelitia tentang Pengaruh Diklat Kepemimpinan terhadap penempatan serta danpaknya terhadap pengembangan karir pegawai kantor wilayah departemen hukum dan ham di wilayah sumatera barat, dari hasil penelitianya diklat kepemimpinan dan penempatan berpengaruh signifikan terhadap pengembangan karir pegawai kantor wilayah departemen hukum dan ham di wilayah sumatera barat.

Trihadi (2003) melukakan penelitian tentang Pengaruh diklat Kepemimpinan dan Karakteristik Pejabat Terhadap Kinerja Dan Pengembangan Karir Pejabat Struktural di Badan Pengkajian Dan Penerapan Teknologi (BPPT), hasil dari penelitianya Diklat Kepemimpinan memberikan pengaruh secara signifikan terhadap pengembangan karir pejabat struktural di BPPT (Trihadi, 2003).

\section{PENUTUP}

\section{Kesimpulan}

Berdasarkan pembahasan yang telah dilakukan pada bab sebelumnya, maka dapat disimpulkan bahwa:

1. Variabel diklat kepemimpinan memiliki pengaruh yang signifikan dan positif terhadap kinerja pegawai dinas koperasi, umkm dan perdagangan Provinsi Sumatera Barat. Hal ini dapat dilihat dari nilai signifikansi dari variabel diklat kepemimpinan adalah sebesar 0,018, maka terbukti bahwa nilai signifikansi lebih kecil dari tingkat signifikan yang digunakan $(0,018<0,05)$ dan koefisien regresi dari diklat kepemimpinan sebesar 0,630 yang bertanda positif menunjukkan bahwa dengan semakin tingginya diklat kepemimpinan akan meningkatkan kinerja sebesar 0,630 dalam setiap satuan.

2. Variabel pengembangan karir memiliki pengaruh yang signifikan dan positif terhadap kinerja pegawai dinas koperasi, umkm dan perdagangan Provinsi Sumatera Barat. Hal ini dapat dilihat dari nilai signifikansi dari variabel 
pengembangan karir adalah sebesar 0,000 maka terbukti bahwa nilai signifikansi lebih kecil dari tingkat signifikan yang digunakan $(0,018<0,05)$ dan koefisien regresi dari pengembangan Karir sebesar 0,987 yang bertanda positif menunjukkan bahwa dengan semakin tingginya pengembangan karir akan meningkatkan kinerja sebesar 0,987 dalam setiap satuan.

3. Variabel diklat kepemimpinan dan pengembangan karir memiliki pengaruh bersama-sama yang signifikan dan positifterhadap kinerja pegawai dinas koperasi, umkm dan perdagangan Provinsi Sumatera Barat. Hal ini dapat dilihat dari nilai nilai $\mathrm{F}$ adalah 44,874 dengan sinifikansi 0,000 .

4. Variabel kinerja pegawai dinas koperasi, umkm dan perdagangan Provinsi Sumatera Barat, dalam kondisi baik, dapat dilihat dari score tingkat capaian responden (TCR) sebesar 87,10. Variabel diklat kepemimpinan dalam kondisi baik, dapat dilihat dari score Tingkat capaian responden (TCR) sebesar 86,30 dan Variabel pengembangan Karir dalam kondisi baik, dapat dilihat dari score Tingkat capaian responden (TCR) sebesar 87,70 .

\section{Saran}

1. Diklat kepemimpinan bagi pegawai dinas koperasi, umkm dan perdagangan Provinsi Sumatera Barat, harus ditingkatkan agar pendidikan, pengalaman kerja, pengetahuan dan keterampilan semakin meningkat untuk menghadapi perkembangan yang semakin pesat.
2. Pengembangan karir pegawai dinas koperasi, umkm dan perdagangan Provinsi Sumatera Barat, agar lebih ditata dengan baik sehingga pegawai memiliki keinginan yang besar untuk mengejar jenjang karir yang lebih baik.

\section{KEPUSTAKAAN ACUAN}

Abdullah, M. (2014). Manajemen dan evaluasi kinerja karyawan. Aswaja Pressindo.

Adha, R. N., Qomariah, N., \& Hafidzi, A. H. (2019). Pengaruh Motivasi Kerja, Lingkungan Kerja, Budaya Kerja Terhadap Kinerja Karyawan Dinas Sosial Kabupaten Jember. Jurnal Penelitian IPTEKS, 4(1), 47-62.

Ambarwati, R. D., \& Baehaqi, I. (2019). Pengaruh Pelatihan dan Pengembangan Karir Terhadap Kinerja PNS di Badan Kepegawaian, Pendidikan dan Pelatihan Daerah Kota Kediri. REVITALISASI, 6(3), 81-88.

Ardyawin, I. (2017). Kompetensi Arsiparis Dalam Pengelolaan Kearsipan Terhadap Pemenuhan Kebutuhan Informasi Masyarakat. JIPI Jurnal Ilmu Perpustakaan Dan Informasi), 2(1), 33-45.

Arif, M. (2019). The Effect of Managerial Competencies, Compesation and Career Planning Toward Employee Performance Through Job Satisfaction at PT. Bank BTPN Tbk Mikro Banking Division (MUR) Pekanbaru Branch. Journal of Management Info, 6(1), 17-21.

Arisanti, K. D., Santoso, A., \& Wahyuni, S. (2019). Pengaruh Motivasi Kerja Dan Disiplin Kerja Terhadap Kinerja 
Karyawan Pada PT Pegadaian (Persero) Cabang Nganjuk. JIMEK: Jurnal Ilmiah Mahasiswa Ekonomi, 2(1), 101-118.

Aydiner, A. S., Tatoglu, E., Bayraktar, E., \& Zaim, S. (2019). Information system capabilities and firm performance: Opening the black box through decision-making performance and business-process performance. International Journal of Information Management, 47, 168-182.

Bagdadli, S., \& Gianecchini, M. (2019). Organizational career management practices and objective career success: A systematic review and framework. Human Resource Management Review, 29(3), 353-370.

Carrion, T. J., Miltenberger, R. G., \& Quinn, M. (2019). Using auditory feedback to improve dance movements of children with disabilities. Journal of Developmental and Physical Disabilities, 31(2), 151-160.

Cho, Y., Bong, H.-C., \& Kim, H.-S. (2019). Examining the development of action learning practice in South Korea. Action Learning: Research and Practice, 16(1), 5-22.

D’Isanto, T., D'Elia, F., Raiola, G., \& Altavilla, G. (2019). Assessment of sport performance: Theoretical aspects and practical indications. Sport Mont, 17(1), 79-82.

Faisal, A., \& Lestari, K. D. (2019). PENGARUH KEPEMIMPINAN, IKLIM ORGANISASI, DAN KEPUASAN KERJA TERHADAP KINERJA. JURNAL ILMLAH $M$ PROGRESS, 9(1).

Habe, H. (2019). ANALISIS KINERJA GURU SMK NEGERI 1 GEDONG
TATAAN

KABUPATEN

PESAWARAN. JURNAL STIE GENTIARAS, 11(1), 1-9.

Hasan, N. (2019). Corak Budaya Birokrasi Pada Masa Kerajaan, Kolonial Belanda Hingga Di Era Desentralisasi Dalam Pelayanan Publik. Jurnal Hukum, 28(2), 1073-1087.

Hasibuan, A. I., Mustapid, M., \& Wijaya, C. (2019). Peran Kepemimpinan Kepala Madrasah dalam Meningkatkan Mutu Pendidikan di MTs. Swasta Miftahul Falah Sunggal Kabupaten Deli Serdang. Anthropos: Jurnal Antropologi Sosial Dan Budaya (Journal of Social and Cultural Anthropology), 4(2), 201-210.

Hidayat, E. S. (2019). KINERJA PELAYANAN BIROKRASI DALAM MEWUJUDKAN KEPUASAN PELANGGAN. Dinamika: Jurnal Ilmiah Ilmu Administrasi Negara, 6(2).

Huselid, M. A. (1995). The impact of human resource management practices on turnover, productivity, and corporate financial performance. Academy of Management Journal, 38(3), 635-672.

Iswandi, I., Suhaimi, S., \& Gaussyah, M. (2017). Kewenangan Badan Pertimbangan Jabatan dan Kepangkatan dalam Mengisi Jabatan Struktural. Kanun: Jurnal Ilmu Hukum, 19(2), 269-284.

Ju, B., \& Li, J. (2019). Exploring the impact of training, job tenure, and educationjob and skills-job matches on employee turnover intention. European Journal of Training and Development, 43(3/4), 214-231.

Kharisma, B. (2014). Good governance sebagai suatu konsep dan mengapa 
penting dalam sektor publik dan swasta: Suatu pendekatan ekonomi kelembagaan. Jurnal Buletin Studi Ekonomi, 19(1), 1-34.

Kusuma, D. M. (2013). Kinerja pegawai negeri sipil (PNS) di kantor badan kepegawaian daerah Kabupaten Kutai Timur. Jurnal Administrasi Negara, 1(4), 1388-1400.

Lestari, P. I., \& Nurislaminingsih, R. (2019). IMPLEMENTASI

UJI KOMPETENSI PUSTAKAWAN PADA JABATAN FUNGSIONAL PUSTAKAWAN DAN ANGKA KREDITNYA DI DINAS KEARSIPAN DAN PERPUSTAKAAN PROVINSI JAWA TENGAH. Jumal Ilmu Perpustakaan, 7(1), 221-230.

Londok, R. N. (2019). Pengaruh Kepuasan Kerja Terhadap Kinerja Karyawan CV. Diagram Global Mandiri Manado. Jurnal Administrasi Bisnis, 9(1), 103-108.

Lubis, S. (2009). Analisis Budaya Kerja dan Kinerja PNS di Lingkungan Pemda Provinsi Sumatera Barat. Jurnal Demokrasi, 8(2).

Marpaung, A., Nurlaela, N., \& Suruan, T. M. (2019). Pengaruh Kompensasi dan Pengembangan Karir terhadap Kinerja Pegawai Negeri Sipil di Dinas Perhubungan Provinsi Papua Barat. Cakrawala Management Business Journal, 2(1), 234-251.

Menteri, P. A. N. (2003). Keputusan Menteri Pendayagunaan Aparatur Negara Nomor 63/KEP/M. PAN, 7, 2003.

Morgeson, F. P., Brannick, M. T., \& Levine, E. L. (2019). Job and work analysis: Methods, research, and applications for buman resource management. Sage Publications.

Munir, M. (2019). Manajemen Bakat Dan Penilaian Kinerja pegawai. Intizam, Jurnal Manajemen Pendidikan Islam, 2(2), 120-134.

Nasfi, N., Iska, S., Nofrivul, N., \& Antoni, A. (2019). FINANCIAL SUSTAINABILITY INTHE ASSESSMENT OF THEFINANCIAL

PERFORMANCE OF WEST SUMATRA SHARIA FINANCING BANK (BPRS). MENARA EKONOMI, 5(1).

Okereke, C. I., \& Nnenna, B. (2011). Training, manpower development and job performance: Perception and relevance among civil servants in Ebonyi State, Nigeria. Journal of Economics and International Finance, 3(6), 399-406.

Pituringsih, E. (2019). FAKTOR-FAKTOR YANG MEMPENGARUHI KESIAPAN PENERAPAN SAP BERBASIS AKRUAL DAN AKUNTABILITAS KINERJA INSTANSI PEMERINTAH (STUDI EMPIRIS PADA PEMERINTAH DAERAH KABUPATEN DOMPU). Jurnal Akuntansi Aktual, $3(1), 62-73$.

Quigley, N. R., \& Tymon Jr, W. G. (2006). Toward an integrated model of intrinsic motivation and career selfmanagement. Career Development International, 11(6), 522-543.

Qurbani, D. (2019). PENINGKATAN KOMPETENSI DOSEN DALAM CARA MENGAJAR MELALUI PENGEMBANGAN TRAINING NEED ANALYSIS (STUDI KASUS 
DI PRODI MANAJEMEN

FAKULTAS EKONOMI

UNIVERSITAS PAMULANG).

JIMF JURNAL ILMLAH MANAJEMEN FORKAMMA), 1(1).

Rieuwpassa, L., Mantiri, M., \& Nayoan, H. (2019). DISIPLIN APARATUR SIPIL NEGARA DALAM PELAYANAN E-KTP DI KANTOR DINAS KEPENDUDUKAN DAN PENCATATAN SIPIL KABUPATEN RAJA AMPAT. JURNAL EKSEKUTIF, 3(3).

Rostanti, L. F., Yuniningsih, T., \& Djumiarti, T. (2016). Analisis Pengembangan Karier Pegawai Negeri Sipil Berdasarkan UndangUndang Nomor 5 Tahun 2014 Tentang Aparatur Sipil Negara di Badan Kepegawaian Daerah Provinsi Jawa Tengah. Journal of Public Policy and Management Review, 5(3), 461-475.

Rozi, V. F., \& Anggraini, M. S. (2019). PENGARUH PENDIDIKAN DAN PELATIHAN TERHADAP KINERJA ASISTEN APOTEKER DI INSTALASI FARMASI RSUD Dr. M. YUNUS BENGKULU. AVICENNA, 14(02), 1-5.

Sahambangung, O., Pioh, N., \& Waworundeng, W. (2019). MANAJEMEN SISTEM APARATUR SIPIL NEGARA (Studi tentang Sistem Merit dalam penempatan jabatan pimpinan tertinggi di lingkungan pemerintahan kabupaten kepulauan sangihe). JURNAL EKSEKUTIF, 3(3).

Sánchez-Marín, G., Meroño-Cerdán, Á. L., \& Carrasco-Hernández, A. J. (2019). Formalized HR practices and firm performance: an empirical comparison of family and non-family firms. The International Journal of Human Resource Management, 30(7), 1084-1110.

Saputro, H., \& Prasetyo, A. (2015). Pengaruh Etos Kerja Islam Terhadap Kepuasan Kerja Karyawan Pada Waroeng Steak and Shake Surabaya. Jurnal Ekonomi Syariah Teori Dan Terapan, 1(3).

Shen, J., \& Zhang, H. (2019). Socially responsible human resource management and employee support for external CSR: roles of organizational CSR climate and perceived CSR directed toward employees. Journal of Business Ethics, 156(3), 875-888.

Stewart, G. L., \& Brown, K. G. (2019). Human resource management. Wiley.

Suparwo, A., Suhendi, H., \& Shobary, M. N. (2019). Pengelolaan Manajemen Keselamatan Dan Kesehatan Kerja Pada UMKM Bandung Indo Garmen. Jurnal Abdimas BSI: Jurnal Pengabdian Kepada Masyarakat, 2(1).

Syukur, M. H. (2014). Diklat Kepemimpinan Pola Baru, Apa, Bagaimana Implementasinya dan Tantangannya. In Forum Diklat (Vol. 4, pp. 1-10).

Trihadi, S. E. Y. (2003). Pengaruh Diklat Kepemimpinan dan Karakteristik Pejabat Terhadap Kinerja dan Pengembangan Karir Pejabat Struktural Badan Pengkajian dan Penerapan Teknologi (Tesis). Jakarta: Program Pasca Sarjana Fakultas Ilmu Sosial dan Ilmu Politik ....

Tumurang, H., \& Tuera, R. (2019). The Needs Of Management Model For 
Professional Competence Training Of Basic School Teachers. In International Conference Primary Education Research Pivotal Literature and Research UNNES 2018 (IC PEOPLE UNNES 2018). Atlantis Press.

Utami, T. K. (2019). ANALISIS TENTANG PENDIDIKAN DAN PELATIHAN TERHADAP PENINGKATAN KOMPETENSI PEGAWAI NEGERI SIPIL DALAM MENGHADAPI MASYARAKAT EKONOMI ASEAN (MEA). Jurnal Hukum Mimbar Justitia, 2(1), 743-758.

Verawati, B., Widaryanti, R., \& Sugiharti, S. (2018). EVALUASI PASCA DIKLAT MEDIS MOW TERHADAP KINERJA
PROVIDER DALAM MEMBERIKAN PELAYANAN KELUARGA BERENCANA. Medika Respati, 13(3).

Wang, J., Zhao, Q., Liu, T., An, M., \& Pan, Z. (2019). Career orientation and its impact factors of general practitioners in Shanghai, China: a cross-sectional study. BMJ Open, 9(3), e021980.

Yusniar, W. O., Suaib, E., \& Amir, M. (2019). ANALISIS PROMOSI JABATAN PEGAWAI NEGERI SIPIL DALAM PENEMPATAN PEJABAT STRUKTURAL DI LINGKUP SEKRETARIAT DAERAH KABUPATEN BUTON UTARA. Publica Jurnal Administrasi Pembangunan Dan Kebijakan Publik), 9(2). 